\title{
Proposal for the management of COVID-19-associated coagulopathy in children
}

\author{
David Ávila-Castro, ${ }^{1}$ Guadalupe Ortiz-Torres, ${ }^{2}$ Berenice Sánchez-Jara, ${ }^{2}$ Teresita Valle-Cárdenas, ${ }^{3}$ \\ Efraín Aquino-Fernández, ${ }^{4}$ Ana I. González-Ávila ${ }^{5}$ and Abraham Majluf-Cruz ${ }^{\text {* }}$ \\ ${ }^{1}$ Instituto Mexicano del Seguro Social, Thrombosis, Hemostasis and Atherogenesis Medical Research Unit, Mexico City; ${ }^{2}$ Instituto Mexicano del \\ Seguro Social, Centro Médico Nacional La Raza, General Hospital, Mexico City; ${ }^{3}$ Secretaría de Salud, Hospital Regional de Alta Especialidad de \\ Ixtapaluca, Hematology Department, State of Mexico; ${ }^{4}$ Secretaría de Salud, Pediatric Specialty Hospital, Hematology Department, Tuxtla Gutiérrez, \\ Chiapas; ${ }^{5}$ Instituto Mexicano del Seguro Social, Regional General Hospital 1, Hematology Department, Mexico City. Mexico
}

\begin{abstract}
SARS-CoV-2 infection (COVID-19) has become a pandemic with a high case fatality rate that mainly affects adults. Most severely ill adult patients develop a coagulopathy that was not described until recently, and which is currently considered a main cause of death. Everything indicates that a similar phenomenon also occurs in children with COVID-19. Anticoagulant treatment has become one of the therapeutic foundations for this infection; however, its implementation in children can be difficult since, until recently, it was not considered in the pediatric population. Evidence regarding the use of anticoagulants in COVID-19 is rapidly generated, changes constantly, it is often difficult to interpret, and can be contradictory. After an extensive review of the published literature, a proposal was generated that offers suggestions for anticoagulant treatment, considering available resources in Mexico.
\end{abstract}

KEY WORDS: COVID-19. Coagulopathy. Pediatric population. Venous thromboembolic disease. Anticoagulants.

\section{Propuesta para el manejo de la coagulopatía asociada a COVID-19 en niños}

\section{Resumen}

La infección por SARS-CoV-2 (COVID-19) se ha constituido en una pandemia con alto índice de letalidad que afecta principalmente a los adultos. La mayor parte de los pacientes adultos graves desarrolla una coagulopatía que no estaba descrita, la cual actualmente se considera la principal causa de muerte. Todo indica que un fenómeno parecido ocurre también en el niño con COVID-19. El tratamiento anticoagulante se ha convertido en uno de los fundamentos terapéuticos de esta infección; sin embargo, su establecimiento en el niño puede ser difícil ya que, hasta hace poco, no estaba considerado en la población pediátrica. La evidencia respecto al uso de anticoagulantes en COVID-19 se genera con rapidez, cambia constantemente, con frecuencia es difícil de interpretar y puede ser contradictoria. Después de una extensa revisión de la literatura publicada, se generó una propuesta que ofrece sugerencias para el tratamiento anticoagulante en la que se consideran los recursos disponibles en México.

PALABRAS CLAVE: COVID-19. Coagulopatía. Población pediátrica. Enfermedad tromboembólica venosa. Anticoagulantes. 


\section{Introduction}

COVID-19 is an acute respiratory infection the clinical evolution of which can be fatal. It is caused by the SARS-CoV-2 virus and affects all age groups; however, clinical evolution can be serious or lethal in elderly patients or in subjects with comorbidities. ${ }^{1}$ The mortality associated with coagulopathy and venous thromboembolic disease (VTD) is very high. Children of all ages are also susceptible to developing COVID-19 and, although there are far fewer documented cases in pediatric patients, the possibility for them to have the same thrombotic outcomes and complications as adults is not ruled out.

As possible protective factors to explain the lower incidence of infection transmission in children, the higher levels of care they are subjected to (greater social isolation in this age group), coexistence of other respiratory viruses that play a competitive role in the airway and, finally, the most important: a lower expression of ACE2 receptors in the lungs, which are necessary for the entry of the virus into the cell and its subsequent replication, can be considered. ${ }^{2}$ However, these mechanisms remain to be proven.

Immunosuppression increases infection-related mortality in all age groups, which suggests that patients with cancer and immunosuppression may be a population at higher risk. On the other hand, as in the adult, pre-existing cardiovascular or lung conditions, obesity, malnutrition, hypertension, diabetes mellitus, cystic fibrosis and asthma have also been described as factors of poor prognosis in children. ${ }^{3}$

Initial observations made in the Chinese population revealed that pediatric patients infected with COVID-19 had a mean age of seven years at diagnosis (interquartile range of two to 13 years), with no predominance of either gender. In another retrospective study, also carried out in China, in 2143 infected children, symptoms were observed to begin at between two and 42 days after the possible infection; $90 \%$ of cases were asymptomatic or had mild to moderate respiratory or digestive symptoms. Subsequently, $2 \%$ of infected children were described to require treatment in intensive care units, with mortality amounting to $0.08 \%$.

In some countries, COVID-19-associated mortality has not been reported in children; however, in China, $5.8 \%$ of the pediatric population developed severe or critical symptoms. ${ }^{4-7}$ In Mexico, by May 22, 336 confirmed cases and 15 deaths had been described in the 0 to 4 years age group; in the 5 to 9 -year-group, there were 195 confirmed cases and three deaths; in the 10 to 14-year-group, there were 300 confirmed cases and three deaths; and in the 15 to19-yeargroup, there were 671 confirmed cases and six deaths. Therefore, in Mexico it is imperative to decrease mortality in the pediatric population.

Patients with the most severe forms of COVID-19 experience multiple organ failure associated with a coagulopathy with characteristics not previously described. There are some laboratory markers of poor prognosis in pediatric patients, such as neutropenia, lymphopenia, and elevated liver enzymes and lactate dehydrogenase, but the manifestations that appear to be the most important are thrombocytopenia (although not at the onset of the disease) and elevated D-dimer. Therefore, the management of COVID-19 is based on the use of antipyretics, antivirals, immunomodulators, viral invasion modulators, respiratory treatment and anticoagulation. ${ }^{1,5,6}$ The latter is included in several guidelines and management proposals, but it is not specifically indicated. There are few consistent suggestions about in-hospital thromboprophylaxis early initiation in pediatric patients in order to decrease the risk of coagulopathy and VTD, as well as on anticoagulant dose adjustments according to patient age, weight and hemostatic parameters. ${ }^{1,6,8}$ The purpose of this document is to suggest a general proposal regarding anticoagulant treatment, which is widely recommended in the patient with COVID-19.

\section{Method}

To carry out this work, evidence published in recent months in relation to COVID-19 basic concepts in adults and children was reviewed. Since evidence and information on the latter is much less, some inferences derived from knowledge in adults were made. Either way, the suggestions for the management of coagulopathy associated with COVID-19, which are the substantial part of this review, are based on recently published information and on existing knowledge about the pharmacology of anticoagulants.

\section{Pulmonary anatomopathological findings}

The lung damage associated with SARS-CoV2-related acute respiratory distress syndrome described in autopsies of adult patients is characterized by diffuse alveolar damage with necrosis, type 2 pneumocyte hyperplasia, T-cell infiltration, fibrin deposits and 
interstitial edema. Histopathological findings show up to nine times more microthrombi formation in the alveolar vasculature in comparison with influenza $A$ infection. Microangiopathy and alveolar occlusion are constants that are observed in these patients. ${ }^{9}$

It appears probable that children have a pathology of acute lung damage similar to that of adults, although their endothelium does not sustain damage of the same magnitude. COVID-19-associated acute lung damage has a severe thromboinflammatory component, characterized by infiltration of neutrophils and lymphocytes into fibrous thrombi, with evidence of neutrophil extracellular trap (NET) formation. It is possible that multiple thrombotic pathways interact to generate thromboinflammation in COVID-19-associated acute lung damage, including endothelial damage, thrombin activation, platelet activation, NET formation, and contact phase activation, which offer multiple targets to mitigate COVID-19 coagulopathy and that potentially could decrease the morbidity and mortality associated with this viral infection. ${ }^{10}$

In one study, the presence of SARS-CoV-2 was demonstrated with a monoclonal antibody against RP3 nucleocapsid protein (NP), the expression of which was prominently revealed on alveolar epithelial cell surface. Histopathological examination revealed diffuse alveolar damage at organizing phase, alveolar lining cells denudation, type II pneumocyte reactive hyperplasia, intra-alveolar fibrinous exudates, interstitial free fibrin and chronic inflammatory infiltrate. Organized fibrin, as well as epithelial damage in alveolar spaces and blood vessels, was observed in most intra-alveolar foci. ${ }^{11}$

On the other hand, in autopsies of patients with COVID-19, diffuse alveolar damage and subclinical small-caliber vessels venous thromboembolic disease have been shown, suggesting that the cause of death may be pulmonary thromboembolism. Lung tissue analysis of 38 necropsies carried out in Lombardy, Italy, described findings consistent with the diffuse exudative and proliferative alveolar disease phases, specifically, capillary congestion, pneumocyte destruction, presence of hyaline membrane, interstitial edema, pneumocyte hyperplasia with reactive atypia and fibrin thrombi. These findings are consistent with the clinical context of coagulopathy seen in COVID-19, which is the reason why anticoagulation is one of the main therapeutic strategies in this disease. Since the lungs and other organs of subjects who die from COVID-19 may still contain live viruses, not performing autopsies is recommended due to the risk of viral spread and transmission by those who carry them out.

Electron microscopy has revealed viral particles within the cytoplasmic vacuoles of pneumocytes. The main finding was the presence of platelet fibrin thrombi in small arteries. ${ }^{2}$

\section{Clinical presentation and diagnosis}

Typical incubation period ranges from one to 14 days, with an average of three to seven days, although longer incubation periods have been described (up to 24 days). Most reports on children indicate that clinical presentation is usually mild and sometimes even asymptomatic, which drives to children contributing to the spread of the pandemic. In most cases described in China, the child had close contact with patients with COVID-19 or was part of a familial group of cases..$^{13}$ Mean age in the largest series of children $(n=2143)$ was seven years (range from 2 to 13 years); 1213 cases were males $(56.6 \%)$. In the pediatric population, $55 \%$ of cases are males, $55 \%$ are asymptomatic or mild, $40 \%$ show moderate-intensity disease, $5 \%$ suffer from the severe form and $<1 \%$ evolves to the critical form. Most children who have required hospital care are younger than three years. ${ }^{14,15}$ COVID-19 is less severe in children, except in infants younger than one year (10\% of cases) and in those with serious underlying conditions. Symptom duration is usually one to two weeks.

In the symptomatic patient, fever and cough are the most common symptoms, to which nasal congestion, dysgeusia, anosmia, rhinorrhea (uncommon), influenza-like illness (nasal obstruction, nasal redness), dry cough, myalgia and fatigue can be added; some patients may experience fever during the course of their illness, and others, remain afebrile. These symptoms can evolve to severe pneumonia. There may be atypical gastrointestinal symptoms: diarrhea, vomiting and abdominal pain. Severe cases present with rapidly progressive dyspnea, septic shock, respiratory distress, renal failure, metabolic acidosis, coagulopathy and multiple organ failure. Some children have only somnolence. In severe cases, severe respiratory distress or hypoxemia may appear during the first week; some rapidly manifest acute respiratory distress syndrome, septic shock, refractory metabolic acidosis, coagulopathy and multiple organ failure (Table 1 and Figure 1). ${ }^{1,5,14}$ The pediatric patient also acquires severe COVID-19 and requires mechanical ventilation. Patients on treatment that affects the immune response can manifest 


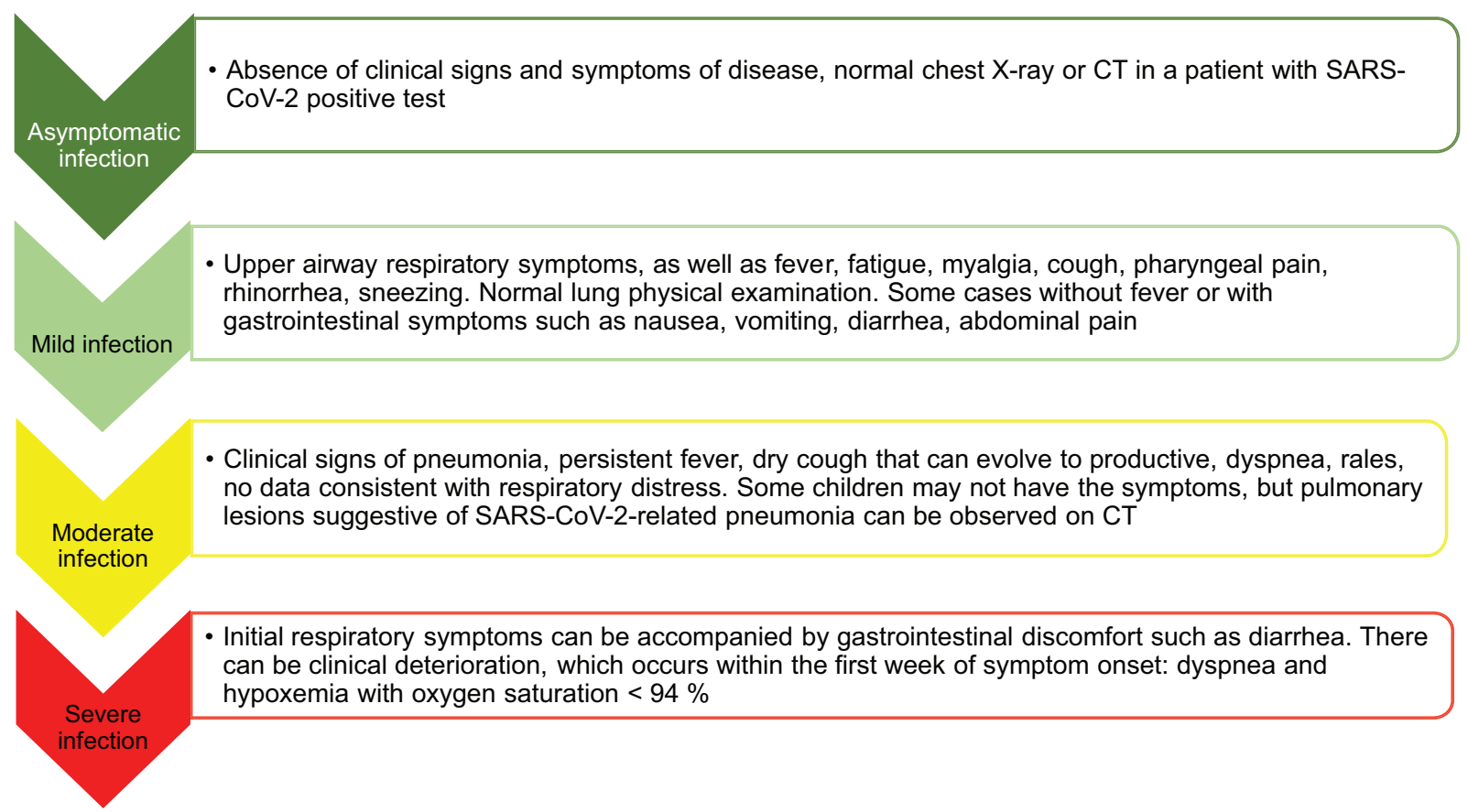

Figure 1. COVID-19 clinical presentation in children.

\author{
Table 1. Critical cases early identification \\ 1. Dyspnea: \\ 2-12 years: $R R>50 /$ minute \\ $1-5$ years: $R R>40 /$ minute \\ Older than 5 years: $R R>30 /$ minute \\ 2. Persistent fever for 3 to 5 days \\ 3. Decreased alertness state, lethargy, consciousness state \\ alteration \\ 4. Myocardial and liver enzymes and lactate dehydrogenase \\ abnormal elevation \\ 5. Unexplainable metabolic acidosis \\ 6. Chest $X$-ray showing bilateral or multilobar infiltration, pleural \\ effusion or rapid progression; tomographic images are \\ consistent with SARS-CoV2-related pneumonia \\ 7. Younger than 3 months \\ 8. Extrapulmonary complications \\ 9. Coinfection with other viruses or bacteria \\ 10. D-dimer and interleukins 6 and 10 increase \\ $\mathrm{RR}=$ respiratory rate.
}

COVID-19 atypical presentations as, for example, those who receive prednisone may not develop fever. Most cases recover within one to two weeks.

The pediatric population at highest risk are children in contact with severe cases of COVID-19, as well as children with serious underlying conditions such as congenital heart diseases, respiratory tract abnormalities, severe malnutrition, anemia, immunodeficiency, prolonged immunosuppressive therapy or cancer. ${ }^{15}$ Other risk factors predictive of evolution to severity are dyspnea, persistent fever for more than three to five days, altered mental status, increased myocardial or liver enzymes and lactate dehydrogenase, unexplained metabolic acidosis, bilateral or multilobular infiltration or pleural effusion on chest X-ray, age younger than three months, extrapulmonary complications and coinfection with other viruses or bacteria. Clinical manifestations in pediatric patients can be classified according to the severity of the clinical presentation (Figures 1 and 2). 2,16,17 Clinical data consistent with serious conditions include the presence of acute respiratory distress syndrome, thromboembolism (pulmonary thromboembolism or ischemic cerebrovascular disease), cardiomyopathy, arrhythmia, cardiogenic shock, acute kidney injury and GillianBarre-like syndrome. ${ }^{2}$

Laboratory test results are important. At early stages, blood count may show no changes or only lymphopenia with thrombocytopenia. Acute phase reactants are elevated: C-reactive protein and erythrocyte sedimentation rate. At initial stages, serum electrolytes and kidney function tests are normal, but can be altered if the disease worsens. In liver function tests, it 


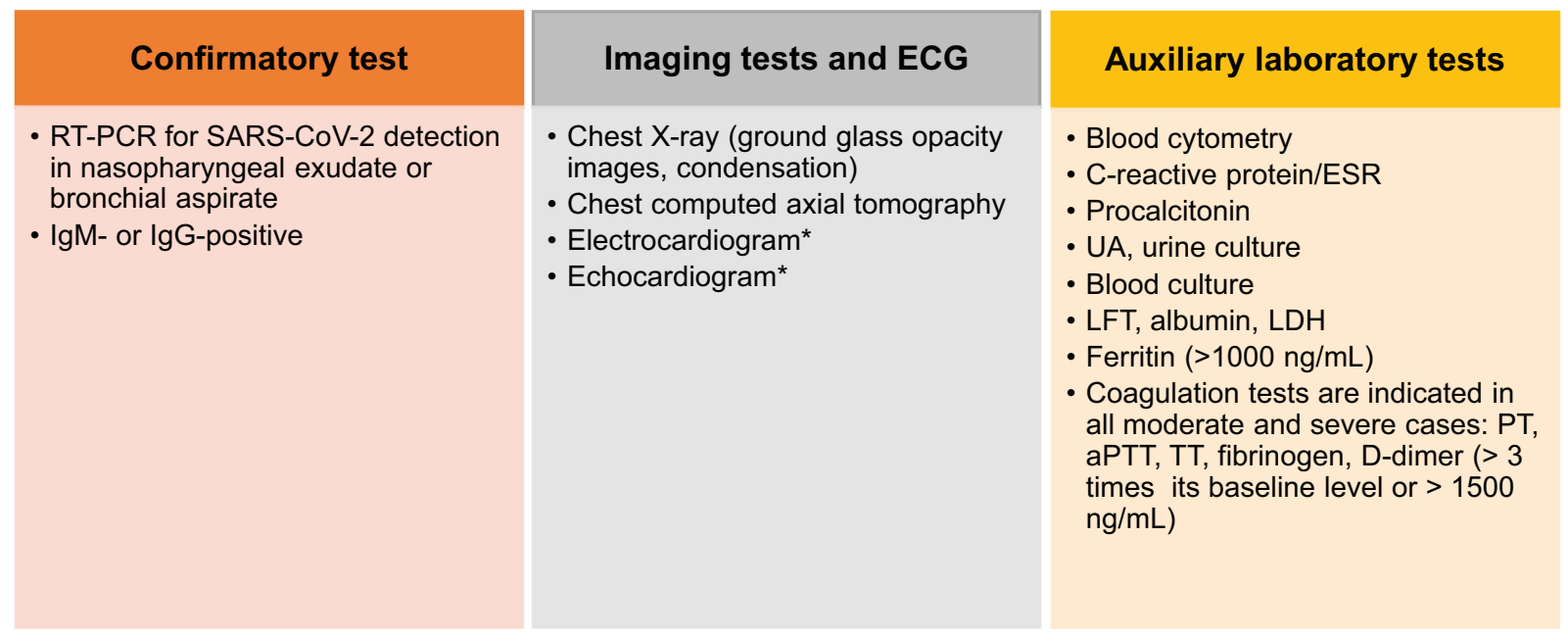

${ }^{*}$ Recommended in case of symptoms similar to those of Kawasaki's disease or if there is previous history of cardiac or pulmonary conditions

Figure 2. COVID-19 paraclinical diagnosis in children. ECG = electrocardiogram, RT-PCR = reverse transcriptase polymerase chain reaction, $\lg M=$ immunoglobulin $M, \lg G=$ immunoglobulin $G, U A=$ urinalysis, $E S R=$ erythrocyte sedimentation rate, $L F T=$ liver function test, $L D H=$ lactate dehydrogenase, $P T=$ prothrombin time, aPTT = activated partial thromboplastin time, $T T=$ thrombin time.

is possible for alanine aminotransferase, aspartate aminotransferase and creatine kinase elevation to be found in $33 \%$ of cases. In critically ill patients, there is an increase in D-dimer and prothrombin time and activated partial thromboplastin time (aPTT) lengthening. There is an increase in lactate dehydrogenase, which has a predictive value for lung damage. Procalcitonin levels may be normal, but their increase suggests bacterial coinfection (in critical cases). Elevated ferritin indicates cytokine storm syndrome or multiple organ damage. ${ }^{18}$

A multi-system inflammatory syndrome associated with uncontrolled cytokine release has been recently reported in subjects younger than 21 years, which is highly similar to Kawasaki's disease (atypical Kawasaki's disease or toxic shock syndrome)., ${ }^{1,2,5,6}$ Those affected have persistent fever, more than half have rashes or maculopapular lesions, abdominal discomfort, cardiomyopathy; respiratory symptoms are unusual. Histopathological findings suggest recent past infection and that the syndrome is the result of a post-inflammatory state. ${ }^{19,20}$

\section{Differential diagnosis}

It is important to differentiate COVID-19 from other common respiratory diseases with similar symptoms. In the differential diagnosis, influenza virus, parainfluenza virus, adenovirus, respiratory syncytial virus, rhinovirus and Mycoplasma pneumoniae infection, as well as bacterial or chlamydia pneumonia, should be distinguished. Some laboratory and imaging tests that are useful for diagnosis are shown in Table 2..$^{15,21}$

\section{Treatment}

Treatment is usually symptomatic: acetaminophen $10-15 \mathrm{mg} / \mathrm{kg}$, oxygen therapy, antiviral therapy (remdesivir), monoclonal antibodies (tocilizumab), and other medications such as glucocorticoids or intravenous immunoglobulin. ${ }^{1,5,14}$ Children with febrile neutropenia and suspected COVID-19 constitute special cases, which should be evaluated in the emergency room to immediately administer broad-spectrum antibiotics. In oncology wards, specific cubicles should be designated for patients with suspected COVID-19, in whom all the precautions established for the management of infectious diseases and those specific to that group of patients should be followed. ${ }^{22,23}$

VTD has a low incidence in children. When it occurs, it generally affects hospitalized patients with risk factors for thrombosis (severe infection, inflammation, dehydration, surgical events, multiple trauma, immobility, use of vascular access and hereditary or acquired thrombophilia)..$^{1}$ It is recommended that each hospital should have algorithms available for the prevention or containment of coagulopathy and VTD and that thrombotic risk factors should be assessed in each patient. ${ }^{6}$ Since this is a new disease, related information is subject to constant updating as knowledge advances. This 
Table 2. COVID-19 differential diagnosis

\begin{tabular}{l|l|l|l|l}
\hline Symptoms & Coronavirus & Common cold & Infiluenza & Seasonal allergy \\
\hline Fever & Common & Rare & Common & Sometimes \\
\hline Fatigue & Sometimes & Sometimes & Sometimes & Common \\
Cough & Common (usually dry) & Moderate & Common (usually dry) & Common \\
Rhinorrhea & No & Common & No & Common \\
Aches & Occasional & Common & Common & No \\
Nasal reddening & Rare & Common & Occasional & Common \\
Swollen throat & Occasional & Common & Occasional & No \\
Diarrhea & Rare & No & Occasional in children & No \\
Headache & Occasional & Rare & Common & Occasional \\
Respiratory distress & In moderate and severe cases & Rare & Rare & Occasional
\end{tabular}

Table 3. Recommendations for anticoagulation in children with COVID-19

\begin{tabular}{|c|c|}
\hline Indication for prophylactic doses & Indication for therapeutic doses \\
\hline $\begin{array}{l}\text { - Any patient with severe COVID-19 who is admitted to } \\
\text { an intensive care unit }\end{array}$ & $\begin{array}{l}\text { - Signs and symptoms suggestive of toxic shock syndrome or multisystem } \\
\text { inflammatory syndrome associated with COVID-19 }\end{array}$ \\
\hline $\begin{array}{l}\text { - Clinical presentation similar to Kawasaki's disease, } \\
\text { where heart involvement is documented }\end{array}$ & $\begin{array}{l}\text { - Imaging evidence of VTD (DVT or PTE) or arterial thrombosis, microangiopathy } \\
\text { or central catheter-associated thrombosis }\end{array}$ \\
\hline - Hereditary or acquired thrombophilia & - Cardiomyopathy, valvulopathy, valve prostheses \\
\hline \multirow[t]{4}{*}{ - Obesity } & $\begin{array}{l}\text { - Continuing anticoagulation is suggested in patients who received it prior to } \\
\text { infection, but now parenterally }\end{array}$ \\
\hline & - Multiple organ failure \\
\hline & - Disseminated intravascular coagulation \\
\hline & $\begin{array}{l}\text { - Other: CRP }>15 \text {, D-dimer }>1500 \mathrm{ng} / \mathrm{mL} \text { or elevation four times its baseline } \\
\text { level in the absence of another finding, IL- } 6>40 \text {, ferritin }>1000 \text {, lymphopenia } \\
<800 \text { cells/ } \mu \mathrm{L}\end{array}$ \\
\hline
\end{tabular}

$\mathrm{CRP}=\mathrm{C}$-reactive protein, DVT $=$ deep vein thrombosis, $\mathrm{PET}=$ pulmonary thromboembolism, VTD $=$ venous thromboembolic disease

document summarizes, to the day of its writing, the evidence to guide on the use of anticoagulation in children with COVID-19. ${ }^{24-29}$ Some recommendations are extrapolated from those for adults, ${ }^{30}$ although anticoagulant treatment in neonates and children differs due to hemostatic variations that affect the pathophysiology of thrombosis and the response to antithrombotic drugs due to pharmacokinetic and pharmacodynamic differences $^{31,32}$ (Tables 3-5).

Low molecular weight heparins (LMWH) are the anticoagulants of choice in pediatrics, both for prophylaxis and for the treatment of VTD. Their advantages include lower monitoring frequency (which is important in patients with limited or complicated venous access), absence of interference with other medications or diet, and low risk for heparin-induced thrombocytopenia and osteoporosis. ${ }^{31}$ Monitoring of LMWH effect is carried out by measuring anti-activated factor $X$ activity (anti-FXa); however, this test is not easily accessible. If an invasive procedure is required, skipping two LMWH doses prior to the intervention is recommended, even before a lumbar puncture. If anti-FXa level is quantified, the test is requested between six and 24 hours after the start of $\mathrm{LMWH}$, the dose of which is adjusted according to the result. Once the desired level is reached, the test can be repeated every week. ${ }^{31}$ 
Table 4. Recommendations for anticoagulation with enoxaparin in children and COVID-19

\begin{tabular}{|l|l|l|l|l|}
\hline Medication & Age & Weight & Therapeutic doses & Prophylactic doses \\
\hline Enoxaparin & $\begin{array}{l}<2 \text { months } \\
>2 \text { months }\end{array}$ & NA & $\begin{array}{c}1.5 \mathrm{IU} / \mathrm{kg} / \text { dose } / 12 \text { hour } \\
1 \mathrm{IU} / \mathrm{kg} / \mathrm{dose} / 12 \text { hour }\end{array}$ & $\begin{array}{c}0.75 \mathrm{IU} / \mathrm{kg} / \mathrm{dose} / 12 \mathrm{hour} \\
0.5 \mathrm{IU} / \mathrm{kg} / \mathrm{dose} / 12 \mathrm{hour}\end{array}$ \\
\hline
\end{tabular}

$\mathrm{NA}=$ does not apply. Adjusting the dose to $0.25 \mathrm{mg} / \mathrm{kg} / 12$ hour is required if there is renal impairment with creatinine clearance $<30 \mathrm{~mL} / \mathrm{minute}$.

Table 5. Recommendations for anticoagulation with unfractionated heparin (UFH)

\begin{tabular}{|c|c|c|c|c|}
\hline \multicolumn{2}{|c|}{ Loading dose } & \multicolumn{3}{|c|}{ Initial maintenance dose } \\
\hline \multicolumn{3}{|c|}{ 75-100 IU/kg, intravenous in 10 minutes } & \multicolumn{2}{|c|}{$\begin{array}{l}\text { - Younger than } 1 \text { year: } 28 \mathrm{IU} / \mathrm{kg} / \mathrm{hour} \\
\text { - Older than } 1 \text { year: } 20 \mathrm{IU} / \mathrm{kg} / \text { hour } \\
\text { - Older than } 18 \text { years: } 18 \mathrm{IU} / \mathrm{kg} / \text { hour }\end{array}$} \\
\hline \multicolumn{5}{|c|}{$\begin{array}{l}\text { Determine aPTT activity } 4 \text { hours after starting the loading dose and adjust the dose according to the following nomogram to } \\
\text { maintain aPTT at between } 60 \text { and } 85 \text { seconds or } 1.5 \text { to } 2.5 \text { times the control aPTT value }\end{array}$} \\
\hline aPTT (s) & Bolus (IU/kg) & Discontinue & Change (IU/kg/h) & Repeat aPTT \\
\hline$<50$ & 50 & 0 & $+20 \%$ & 4 hours \\
\hline $50-59$ & 0 & 0 & $20 \%$ & 4 hours \\
\hline $60-85$ & 0 & 0 & 0 & 4 hours \\
\hline $85-95$ & 0 & 0 & $-10 \%$ & 24 hours \\
\hline $96-120$ & 0 & 30 minutes & $-10 \%$ & 4 hours \\
\hline$>120$ & 0 & 60 minutes & $-15 \%$ & 4 hours \\
\hline \multicolumn{5}{|c|}{$\begin{array}{l}\text { Preparing the UFH maintenance infusion at the following concentrations is recommended: } \\
\text { - Children weighing less than } 10 \mathrm{~kg}: 80 \mathrm{IJ} / \mathrm{mL} \\
\text { - Children weighing more than } 10 \mathrm{~kg} ; 40 \mathrm{IU} / \mathrm{mL} \\
\text { Preparing the heparin maintenance infusion according to the following concentration is recommended: }\end{array}$} \\
\hline
\end{tabular}

If prophylactic anticoagulation is prescribed, using it until the patient is discharged from the intensive care unit is suggested, i.e., once he is hemodynamically stable and without hemostatic compromise. ${ }^{1,5,6}$ The recommended anticoagulation period is seven days. If anticoagulation is therapeutic, the anticoagulation period ranges between three and six months, depending on the underlying event that caused the thrombosis, or until resolution of the hypercoagulable state. It can be changed to oral anticoagulation when the patient is clinically stable, out of severity state, and oral route has been reestablished.

It should be remembered that only vitamin $\mathrm{K}$ antagonists (VKA) are recommended in children and that, for proper control, monitoring should be carried out using the international normalized ratio (INR). VKA treatment is individualized and is not suggested in patients younger than one month. In children under one year of age, higher doses and frequent adjustments are required, due to feeding and a lower generation of endogenous thrombin in comparison with adults. It is recommended that children receiving VKA maintain an INR at between 2 and 3 for all indications. ${ }^{31}$ Even when VKAs are recommended, it will be necessary to assess whether their use in COVID-19 is safe and if, according to the pathophysiology of the thromboinflammatory phenomenon associated with the infection, they could really have any beneficial function. ${ }^{10}$ Based on the results of a recent study, it is feasible to consider the use of rivaroxaban for chronic anticoagulation after discontinuing anticoagulation with enoxaparin. ${ }^{29}$

\section{Conclusions}

The suggestions we offer in this document do not address the problem of arterial thrombosis since, unquestionably, its impact is currently much lower. Of course, they are not definitive, since information 
changes from one week to another; therefore, the pediatrician should remain updated at all times about this problem. The presented proposal was prepared taking into account the anticoagulants available in Mexico and their pediatric indications. Like any guideline, it is only a compilation of suggestions published in the literature and, therefore, in no way substitutes clinical judgment, medical experience and decisions made at patient bedside considering his/her individual needs and available resources.

\section{Conflict of interests}

The authors declare that they have no conflicts of interest.

\section{Funding}

The authors did not receive any sponsoring for carrying out this article.

\section{Ethical disclosure}

Protection of people and animals The authors declare that no experiments were performed on humans or animals for this research.

Confidentiality of data The authors declare that no patient data appear in this article.

Right to privacy and informed consent The authors declare that no patient data appear in this article.

\section{References}

1. Hennon TR, Penque MD, Hicar MD, Abdul-Aziz R, Alibrahim OS, Gómez-Duarte OG, et. al. COVID-19 associated Multisystem Inflammatory Syndrome in Children (MIS-C) guidelines; a Western New York approach. Prog Ped Cardiol. 2020:1-5.

2. Dong $Y$, Mo X, Hu Y, Qi X, Jiang F, Jiang Z, et al. Epidemiological characteristics of 2143 pediatric patients with 2019 coronavirus disease in China. J Emerg Med. 2020;58:712-713.

3. Sinha IP, Harwood R, Semple M, Hawcutt DB, Thursfield R, Narayan O, et. al. COVID-19 infection in children. Lancet Respir Med. 2020;8:446-447.

4. Zhang L, Zhu F, Xie L, Wang C, Wang J, Chen R, et. al. Clinical characteristics of COVID-19-infected cancer patients: a retrospective case study in three hospitals within Wuhan, China. Ann Oncol. 2020;31:894-901.

5. Liguoro I, Pilotto C, Bonannil M, Ferrari ME, Pusiol A, Nocerino A, et. al. SARS-COV-2 infection in children and newborns: a systematic review. Eur J Pediatr. 2020;1:1-8.

6. National Institutes of Health [Online]. USA: Coronavirus disease 2019 (COVID-19). Treatment guidelines; 2020.

7. Zheng F, Liao C, Fan QH, Chen HB, Zhao XG, Xie ZG, et. al. Clinical characteristics of children with coronavirus disease 2019 in Hubei, China. Curr Med Sci. 2020;40:1-6.

8. He Y, Lin Z, Tang D, Yang Y, Wang T, Yang M. Strategic plan for management of COVID-19 in pediatric hematology and oncology departments. Lancet Hematol. 2020;7:359-362.
9. Ackermann M, Verleden S, Kuehnel M, Haverich A, Welte T, Laenger F, et. al. Pulmonary vascular endothelialitis, thrombosis, and angiogenesis in Covid-19. N Engl J Med. 2020;1:1-9.

10. Mitchell WB. Thromboinflammation in COVID-19 acute lung injury. Paed Resp Rev. 2020. DOI: 10.1016/j.prrv.2020.06.004

11. Zhang H, Zhou P, Wei $Y$, Yue H, Wang Y, Hu M, et. al. Histophatologic changes and SARS-COV-2 inmunostaining in the lung of patients with Covid-19. Ann Intern Med 2020;172:629-632.

12. Zhe $X$, Shi $L$, Wang $Y$, Zhang J, Huang $L$ Zhang $C$, et. al. Pathological findings of COVID-19 associated with acute respiratory distress syndrome. Lancet Respir Med. 2020;8:420-422.

13. Chan JF, Yuan S, Kok KH, Kai-Wang To K, Chu H, Yang J, et al. A familiar cluster of pneumonia associated with the 2019 novel coronavirus indicating person-to-person transmission: A study of a family cluster. Lancet. 2020;395:514-523.

14. Castagnoli R, Votto M, Licari A, Brambilla I, Bruno R, Perlini S, et al. Severe acute respiratory syndrome coronavirus (SARS-CoV-2) infection in children and adolescents: a systematic review. JAMA Pediatr. 2020. DOI: 10.1001/jamapediatrics.2020.1467

15. Lu X, Zhang L, Du H, Zhang J, Li YY, Qu J, et al. SARS-CoV-2 infection in children. N Engl J Med. 2020;382:1663-1665.

16. Qiu H, Wu J, Hong L, Luo Y, Song Q, Chen D. Clinical and epidemiological features of 36 children with coronavirus disease 2019 (COVID-19) in Zhejiang, China: An observational cohort study. Lancet Infect Dis. 2020;20:689-696.

17. Dong Y, Mo X, Hu Y, Qi X, Jiang F, Jiang Z, Tong S. Epidemiology of COVID-19 among children in China. Pediatrics. 2020;145:e20200702.

18. She J, Liu L, Liu W. COVID-19 epidemic: disease characteristics in children. J Med Virol. 2020;92:747-754.

19. Jones VG, Mills M, Suarez D, Hogan CA, Yeh D, Segal JB, et. al. COVID-19 and Kawasaki disease: novel virus and novel case. Hosp Pediatr. 2020;10:537-540.

20. Riphagen S, Gómez X, González-Martínez C, Wilkinson N, Theocharis P. Hyperinflammatory shock in children during COVID-19 pandemic. Lancet. 2020;395:1607-1608.

21. Pavone P, Giallongo A, La Rocca G, Ceccarelli M., Nunnari G. Recent COVID-19 outbreak: effect in childhood. Infect Dis Trop Med. 2020;6:1-4.

22. Choi SH, Kim HW, Kang JM, Kim DH, Cho EY. Epidemiology and clinical features of coronavirus disease 2019 in children. Clin Exp Pediatr. 2020;63:125-132.

23. Maharaj AR, Wu H, Hornik C, Balevic SJ, Hornik CD, Smith B, et al. Simulated assessment of pharmacokinetically guided dosing for investigational treatments of pediatric patients with coronavirus disease 2019. JAMA Pediatr. 2020. DOI: 10.1001/jamapediatrics.2020.2422

24. Mon EY, Mandelia Y. Managing COVID-19 infection in pediatric patients. Clev Clin J Med. 2020;1:1-3.

25. Zimmermann $P$, Curtis N. Coronavirus infections in children including COVID-19. Pediatr Infect Dis J. 2000;39:355-368.

26. Wang $L$, Shi $Y$, Xiao T, Fu J, Feng $X, M u ~ D$, et. al. Chinese expert consensus on the perinatal and neonatal management for the prevention and control of the 2019 novel coronavirus infection. Ann Transl Med. 2020;8:47.

27. Carvalho AP, Carlotti P, de Carvalho WB, Johnston C, Souza Rodriguez I, Figueiredo Delgado A. Covid-19 diagnostic and management protocol for pediatric patients. Clinics. 2020;75:1-5.

28. Monagle P, Chan AKC, Goldenberg NA, Ichord RN, Journeycake JM, Nowak-Göttl U, et al. Antithrombotic therapy in neonates and children: Antithrombotic therapy and prevention of thrombosis, 9th Ed: American College of Chest Physicians Evidence-Based Clinical Practice Guidelines. Chest. 2012;141:e737S-e801S.

29. Male C, Lensing AWA, Palumbo JS, Kumar R, Nurmeevl, Hege K, et. al. Rivaroxaban compared with standard anticoagulants for the treatment of acute venous thromboembolism in children: A randomised, controlled, phase 3 trial. Lancet Haematol. 2020;7:e18-e27.

30. Barrett CD, Moore HB, Yaffe MB, Moore EE. ISTH interim guidance on recognition and management of coagulopathy in COVID-19. J Thromb Haemost. 2020;18:1023-1026.

31. Altuna D, Bonduel M. Tromboembolismo venoso en pediatría. In: Colorio C, Giumelli C, Forastiero R, Penchasky D, Sánchez-Luceros A, publishers. Manejo práctico del tromboembolismo venoso. Argentina: Grupo Cooperativo Argentino de Hemostasia y Trombosis. Available at: http://www.grupocaht.com/tev2/

32. Manco-Johnson MJ, Grabowski EF, Hellgreen M, Kemahli AS, Massicotte MP, Munteanet W, et al. Recommendations for tPA thrombolysis in children. On behalf of the Scientific Subcommittee on Perinatal and Pediatric Thrombosis of the Scientific and Standardization Committee of the International Society of Thrombosis and Haemostasis. Thromb Haemost. 2002;88:157-158. 